\title{
FEATURES OF AN ECONOMIC APPROACH AT RESEARCH OF CORRUPTION PHENOMENON
}

\author{
ОСОБЕННОСТИ ЭКОНОМИЧЕСКОГО ПОДХОДА ПРИ ИССЛЕДОВАНИИ \\ ФЕНОМЕНА КОРРУПЦИИ
}

M.O. Izotov, Researcher

M.О. Изотов, научный стотрудник

Orel State Agrarian University, Orel City, Russia

Орловский государственный аграрный университет, г. Орёл, Россия

Phone: +7 (920) 812-90-64, E-mail: $\underline{\max 198522 @ \text { mail.ru }}$

Received August 10, 2012

\begin{abstract}
In article features of an economic approach are considered when developing the anti-corruption measures directed on restriction of possibilities of any discretion and excessive intervention of civil servants in economic activity, including through differentiation of functions and specification of competences. The special urgency of researches of a problem of corruption as special social phenomenon is noted.
\end{abstract}

\section{АННОТАЦИЯ}

В статье рассмотрены особенности экономического подхода при разработке антикоррупщионных мер, направленных на ограничение возможностей произвольного усмотрения и чрезмерного вмешательства государственных служащзи в хозяйственную деятельность, в том числе через разграничение функций и уточнение областей компетенции. Отмечена особая актуальность исследований проблемь коррупции как особого социального явления.

\section{KEY WORDS}

Corruption; Social and economic researches; Phenomenon; Model; Economic approach.

\section{КЛЮЧЕВЫЕ СЛОВА}

Коррупция; Социально-экономические исследования; Феномен; Модель; Экономический подход.

В последнее время в современном российском обществе стала крайне актуальной проблема исследования коррупции как особого социального явления. Ее изучением занимается целый ряд социальных и гуманитарных наук, каждая из которых вносит свой существенный вклад в развитие проблематики коррупции и борьбы с ней.

В экономической науке, в рамках неоинституциональной школы в 70-е гг. ХХ в., сформировался свой подход в исследовании феномена коррупции. Согласно ему, коррупция изучается исходя из посылки, что она является рациональной (и даже нормальной) разновидностью поведения, направленной на нахождение оптимального способа реализации интересов в условиях ограниченности ресурсов. То есть, «решение дать (взять) взятку опи- рается на ту же калькуляцию затрат и выгод, что и любое другое экономическое решение» [1]. Например, у С. Роуз-Аккермана, одного из основателей данного подхода, коррупция определяется как «разновидность экономического поведения в условиях риска, обусловленного совершением преступления и возможным наказанием за него» [2].

Описывается коррупционное поведение при помощи модели «принципал - агент», детально описанную в работах Эггертсона [3]. Эта модель характеризует взаимоотношения трех участников: принципала, агента и клиента. Принципалом является лицо или организация, ставящие перед собой цели и обладающие ресурсами для их реализации. В его роли могут выступать какой-либо государственный орган или ведомство, государство или общество в 
целом. Для реализации поставленных перед собой целей принципал нанимает агента, которым на деле являются государственные служащие. Агенту задаются цели, передаются необходимые ресурсы (властные, финансовые и т.д.) и назначается вознаграждение за выполненную работу. В дальнейшем принципал, наняв агента, может контролировать его деятельность, чтобы обеспечить достижение необходимого результата и адекватное для этого расходование переданных агенту ресурсов. Клиентом является лицо, группа, организация, которые для решения своих проблем, целей нуждаются в использовании вверенного агенту ресурса и поэтому вынуждены обращаться к нему (например, граждане, предприниматели, обратившиеся за помощью к чиновнику). Коррупцией в рамках этой модели выступают такие действия агента, при котором он использует ресурсы принципала не для решения задач последнего, а для достижения собственных целей. Клиенты при этом выступают в роли взяткодателей, вступивших в сговор с агентом для решения своих проблем за передаваемую ему взятку.

Сами же коррупционные ситуации в рамках описываемой модели возникают из-за наличия асимметрии в доступе к информации, существующей между агентом и принципалом. Агент по сравнению с принципалом владеет большей информацией о состоянии текущих дел, может утаивать ее и использовать в личных, в том числе и корыстных целях. В результате разрыв в доступе к информации приводит к тому, что чиновник имеет монопольное право распоряжаться государственным ресурсом в условиях отсутствия контроля со стороны государства и общества, а также маловероятного риска наказания за коррупционную деятельность. Именно в таких ситуациях возникают коррупционные сделки. Данное обстоятельство Р. Клитгаард наглядно изобразил в виде формулы: «Коррупция = монополия + свобода действий - подотчетность» [4].

Большое место в экономической теории при исследовании феномена коррупции уделяется проблеме взаимоотношений бизнеса и власти. Государственные служащие обладают властным, административным ресурсом, бизнесмены - финансовым. И те, и другие заинтересованы в получении доступа к ресурсу, которым они не владеют.

Представители власти, чтобы получить доступ к материальным средствам бизнесменов с целью личного обогащения, могут ока- зывать на них давление, создавая административные барьеры. Под административными барьерами при этом понимаются «препятствия, возникающие при организации и осуществлении предпринимательской деятельности вследствие введения органами государственного (федерального или регионального) и муниципального управления дополнительных бюрократических процедур, мешающих ведению бизнеса и предусматривающих возмездный характер их преодоления» [5]. Создание и воспроизводство административных барьеров создает для чиновников условия для коррупционного воздействия на бизнесменов, включающего широкий спектр действий: от вымогательства отдельных взяток, до полного «захвата бизнеса». Последнее представляет собой «совокупность стратегий и тактик власти, с помощью которых власть в лице своих представителей или даже организаций стремится обеспечить теневой контроль над бизнесом с целью извлечения административной ренты» [6]. В этом случае рента обеспечивается не получаемыми взятками, а непосредственно источниками, из которых они произрастают, бизнесом и доходом от него.

Бизнесмены, как и чиновники, часто выступают инициаторами коррупционных взаимоотношений с представителями власти, так как последние, используя свой властный ресурс, могут искусственно создавать выгодные условия для ведения предпринимательской деятельности. Получая от бизнесмена определенное вознаграждение, чиновник может осуществлять защиту, покровительство интересам его фирмы в виде:

- защиты от законного и незаконного вмешательства в деятельность частного предприятия со стороны государственных контролирующих и правоохранительных органов, а также от организованных преступных групп;

- создания условий для получения необходимых при ведении бизнеса налоговых и подобных им льгот (производственных помещений, кредитов, оборудования, материалов);

- формирования путем предоставления необходимых информации и связей для фирмы положения, при котором она в условиях конкурентного рынка фактически становится его монополистом и т. д.

«Предприниматель, который лучше манипулирует... связями с чиновниками, оказывается более успешным, чем тот, кто озабочен лишь производством» [7], - отмечает данное обстоятельство Эрнандо де Сото. Более того, 
как считает М. Олсон, бизнесмены стремятся не просто откупиться от чиновника отдельными взятками, но и полностью подкупить государственный аппарат, внедрить в него своих людей и заставить их работать на себя: «...рано или поздно, частный сектор (поскольку все или почти все его представители имеют побудительные мотивы к нарушению антирыночных установок или к подкупу чиновников) делает правительство коррумпированным и неэффективным» [8]. Здесь уже идет речь об обратном, противоположном процессу «захвата бизнеса» процессу «захвата государства», предполагающему «установление теневого контроля за принятием решений в пользу «своего» бизнеса на высших уровнях власти» [9].

Результатом взаимной мотивации бизнесменов и чиновников к неформальному сотрудничеству является сращивание их деятельности и создание устойчивых коррупционных связей между ними. Поэтому, с точки зрения экономической науки, важной задачей в борьбе с коррупцией является создание препятствий для сращивания бизнеса и власти.

Основные причины распространения коррупции в обществе экономисты видят в чрезмерном и неэффективном вмешательстве государства в экономические процессы, создающем благоприятные условия для развития произвола в деятельности чиновников. Чем большее количество запретов государство устанавливает для своих граждан, тем чаще им приходится сталкиваться с трудностями при взаимодействии с государственными служащими и тем вероятней становится ситуация дачи - по- лучения взятки как способа решения того или иного вопроса, проблемы.

Поэтому в рамках экономического подхода предлагаются антикоррупционные меры, которые должны быть направлены на ограничение возможностей произвольного усмотрения и чрезмерного вмешательства государственных служащих в хозяйственную деятельность простых граждан. Например: разграничение функций, уточнение областей компетенции и уменьшение сфер действия личного усмотрения служащего; упорядочение процедур взаимодействия чиновников с гражданами; усиление внутреннего и внешнего контроля за деятельностью государственных служащих и т.д. Также, в экономической науке отмечается, что антикоррупционная политика государства должна приносить для общества меньшие издержки, чем сама коррупция, «поскольку затраты на искоренение взяточничества могут превосходить соответствующие прибыли» .

Таким образом, в экономике под коррупцией принято понимать разновидность поведения государственных служащих, направленного на извлечение выгоды за счет использования государственных ресурсов в личных целях. Причины размаха коррупционной деятельности видятся в чрезмерном и неэффективном вмешательстве государства в экономическую жизнь общества. Поэтому основные меры борьбы с коррупцией направлены на уменьшение произвола и чрезмерного вмешательства чиновников в хозяйственную деятельность простых граждан.

\section{БИБЛИОГРАФИЯ}

Барсукова, С. Ю. Коррупция: научные дебаты и российская реальность // Общественные науки и современность, 2008. - №5 - c. 37.

Роуз-Аккерман, С. Коррупция и государство. Причины, следствия, реформы / пер. с англ. О. А. Алякринского. - М.: Логос, 2003. - с.27.

Эггертсон, Т. Экономическое поведение и институты / Пер. с англ. М. Я. Каждана, А. Н. Нестеренко. - М.: Дело, 2001. - 408 c.

Klitgaard, R. Corruption // Finance \& Development, 1998. - March - p. 4.

Дегтярев А., Маликов Р. Коррупционная основа административных барьеров // Вопросы экономики, 2003. - №11 - с.78.
Проява, С. М. Экономизация коррупции. Механизм противодействия. - М.: ЮНИТИ - ДАНА: Закон и право, 2008. - c. 104.

Сото, Э. де Иной путь. Невидимая революция в третьем мире. - M.: Catalaxy, 1995. - c. 189.

Олсон, М. Возвышение и упадок народов: Экономический рост, стагфляция, социальный склероз. - Новосибирск: ЭКОР, 1998. - с. 401.

Дегтярев А., Маликов Р. Институциональный анализ деловой коррупции в России // Вопросы экономики, 2005. - №10 - с. $105-106$. 